\title{
Preparation of Adsorbents by Pyrolysis of Sludge Mixed With Steel Slag and Study on Adsorption of Chromium lons in Water
}

\author{
Xiaowen Qi, Enze Zhou *, Xuefei Wu, Siyi Luo* and Yanggang Song \\ College of Environmental and Municipal Engineering, Qingdao University of Technology, Qingdao, China
}

In this study, the dewatered sludge from the sewage plant and the open-hearth steel slag of the steel plant are used as raw materials. As two wastes, they were mixed and pyrolyzed to prepare a composite absorbent. Further, the adsorption mechanism of the adsorbent to chromium ions in the sewage is explored. The pyrolysis reaction behavior of sludge mixed with steel slag was studied by the thermogravimetric analysis technology. SEM, BET, and

OPEN ACCESS

Edited by:

Xuezhong He,

Guangdong Technion-Israel Institute of Technology, China

Reviewed by:

Jiuyang Lin,

Fuzhou University, China

Sathish Sanjeevi,

National Energy Technology

Laboratory (DOE), United States

*Correspondence:

Enze Zhou

zhouenze@126.com

Siyi Luo

luosiyi666@126.com

Specialty section:

This article was submitted to Advanced Clean Fuel Technologies, a section of the journal

Frontiers in Energy Research

Received: 06 September 2021

Accepted: 06 December 2021

Published: 05 January 2022

Citation:

QiX, Zhou E, Wu X, Luo S and Song Y (2022) Preparation of Adsorbents by Pyrolysis of Sludge Mixed With Steel Slag and Study on Adsorption of

Chromium lons in Water.

Front. Energy Res. 9:771603. doi: 10.3389/fenrg.2021.771603
XPS were used to analyze the specific surface area, pore size distribution, and pore structure characteristics of pyrolysis products, respectively. Moreover, a comprehensive analysis of the adsorbent was carried out for the adsorption mechanism of hexavalent chromium ions. The results show that the addition of steel slag promotes the pyrolysis of the sludge in each stage. When the content of steel slag is $80 \%$, the increases of reaction rate are the most obvious with the largest increase of weight loss rate in each stage. The SEM results show that the enrichment of sludge on metal oxides is enhanced in the hightemperature range $\left(600-700^{\circ} \mathrm{C}\right)$. Besides, when the content of steel slag is $40-60 \%$, the mixture's growth rate of the specific surface area can reach $600 \%$ and the growth rate of total pore volume can reach $350 \%$ (the situations of sludge as the baseline). Regarding the measurement of $\mathrm{Cr}(\mathrm{VI})$, the adsorption rate of the steel-slag solution is $50.93 \%$ and that of the sludge solution is $69 \%$. However, the adsorption rate can be increased to $95 \%$ when the steel slag and sludge were mixed as an adsorption solution. In conclusion, the adsorption mechanism of $\mathrm{Cr}(\mathrm{Vl})$ by additives is controlled by both physical and chemical processes. The present study provides a theoretical basis and technical support for the scientific and reasonable utilization of sludge and steel slag.

Keywords: sewage sludge, steel slag, adsorbent, pyrolysis kinetics, $\mathrm{Cr}(\mathrm{VI})$ adsorption

\section{INTRODUCTION}

Sewage sludge is one of the main byproducts after sewage treatment. As a kind of high-wet-base biomass, it contains not only organic residues, inorganic particles, and colloids (Wei et al., 2011) but also a large amount of toxic and harmful substances such as pathogenic bacteria (Fernando and Fedorak, 2005), dioxins (Raheem et al., 2018), and heavy metal ions (Fang et al., 2016). If it is discharged without treatment, it is very easy to cause secondary pollution to groundwater and soil, endangering human health directly (Bondarczuk et al., 2015). Most of the domestic and foreign sludge treatment technologies and equipment are mainly aimed at the safe disposal of sludge 
digestion. The disposal methods mainly include anaerobic digestion, sanitary landfill, incineration treatment, and water body disposal (Raheem et al., 2018; Stunda-Zujeva et al., 2018), which have not produced actual economic benefits and formed valuable commodities. Steel slag is the main byproduct of the iron and steel production process, which is composed of various oxides oxidized by impurities such as silicon, manganese, phosphorus, and sulfur in pig iron in the smelting process and salts generated by the reaction of these oxides and solvents (Piatak et al., 2015). At present, the utilization of steel slag is mainly consumed in the direction of building materials (Liu et al., 2020; Sridhar and Sastri, 2021), and the efficient development and utilization of steel slag resources has been the focus of attention of the metallurgical industries around the world for many years (Diao et al., 2016).

Due to the high content of carbon, hydrogen, nitrogen, phosphorus, and other resource elements, sludge has become a key resource, which can be used as a raw material. It is possibly a valuable strategy to convert it into biochar through the heat treatment technology (Bora et al., 2020). Pyrolysis, a typical heat treatment technology (Barry et al., 2019), which can reduce the volume of sludge, kill microorganisms, and parasite eggs and transform heavy metals from a weakly bound state to a stable state, ensures the security of applications (Jin et al., 2016). The bio-oil and pyrolysis gas produced by pyrolysis are potentially for reusing (Cao and Pawlowski, 2012). The biological carbon can be used as a fertilizer or made into an adsorbent, the whole process of which has higher resource utilization and better environmental protection.

In recent years, pyrolysis of sludge into an adsorbent has attracted the attention of many scholars. However, the porosity, specific surface area, and adsorption capacity of the adsorbents produced by pyrolysis of sewage sludge are far behind those of commercial activated carbon adsorbents. In order to improve the adsorption performance of sludge adsorbents, some scholars used other biomass for co-pyrolysis such as cotton stalks (Wang et al., 2019), rice husks (Yang et al., 2010), and bagasse (Lin et al., 2017). Some scholars have tried to add chemical agents for activation during the pyrolysis process. $\mathrm{Li}$ et al. used $\mathrm{ZnCl}_{2}$ and $\mathrm{KOH}$ to activate the sludge to prepare desulfurizing adsorbents ( $\mathrm{Li}$ et al., 2014); the capacity of sulfur is $7.7 \mathrm{mg} / \mathrm{cm}^{3}$, the maximum value of iodine is $409.95 \mathrm{mg} / \mathrm{g}$, and the desulfurization activity is better than that of industrial activated carbon. The co-pyrolysis technology was applied to municipal sewage sludge and hazelnut shells with the alkaline activating agent $\mathrm{K}_{2} \mathrm{CO}_{3}$ by Zhao et al. (2018), and they found that after co-pyrolysis at $850^{\circ} \mathrm{C}$, the specific surface area reached $1990.23 \mathrm{~m}^{2} / \mathrm{g}$ and the iodine adsorption number was $1068.22 \mathrm{mg} / \mathrm{g}$. Luo et al. (2020) activated the sludge with $\mathrm{KOH}$ and $\mathrm{H}_{2} \mathrm{SO}_{4}$ and found that both $\mathrm{KOH}$ and $\mathrm{H}_{2} \mathrm{SO}_{4}$ can reduce the pyrolysis activation energy and promote the release of volatiles. However, from the perspective of literature review, there is no mention of adding steel slag in the pyrolysis process of sludge.

The metal oxides such as $\mathrm{CaO}, \mathrm{Al}_{2} \mathrm{O}_{3}, \mathrm{Fe}_{2} \mathrm{O}_{3}$, and $\mathrm{MgO}$ and $\mathrm{a}$ large amount of $\mathrm{Fe}$ contained in the steel slag all have certain catalytic activity. During the pyrolysis of pine wood chips, Lee added steel slag as an adsorbent, which significantly accelerated the reaction rate and promoted the generation of $\mathrm{CH}_{4}$ and $\mathrm{H}_{2}$ (Lee et al., 2020). About $40 \%$ of the open-hearth steel slag is $\mathrm{CaO}$. Zuo found that in the study of the reduction characteristics of copper slag using biochar as a reducing agent, $\mathrm{CaO}$ can improve the reduction reaction of $2 \mathrm{FeO} \cdot \mathrm{SiO}_{2}$ in copper slag and significantly reduce Gibbs free energy (Zuo et al., 2019). As a catalyst, the performance of steel slag is acceptable to improve the adsorption. Meanwhile, the application of steel slag is an environmental-friendly method for addressing the waste pollution.

In this study, steel slag mixed with sewage sludge was used for pyrolysis preparation of the adsorbent to adsorb $\mathrm{Cr}$ (VI), which is extremely harmful to the human body in sewage. The steel slag helps the sludge base to produce a larger adsorption surface area. At the same time, certain components contained in the steel slag undergo oxidation-reduction reactions with $\mathrm{Cr}(\mathrm{VI})$, which helps the adsorption of $\mathrm{Cr}(\mathrm{VI})$. The pyrolysis behavior of the sludge mixed with steel slag was investigated by the thermogravimetric analysis technology, combined with the e-sports scanning technology, the specific surface area analysis technology, X-ray photoelectron spectroscopy (XPS), and other means to analyze the adsorption mechanism of sludge-based adsorbents. The concept of "treating waste with waste" has been a successful realization and has provided a feasible path for the development and utilization of sludge and steel slag.

\section{MATERIALS AND METHODS}

\section{Materials Preparation}

In this study, sewage sludge with a moisture content of $78 \%$ was obtained from a sewage treatment plant in Qingdao, China. The sewage sludge was dried at $105^{\circ} \mathrm{C}$ for $24 \mathrm{~h}$ and then ground into a powder $(<80 \mu \mathrm{m})$. The industrial analysis and elemental analysis of the sample are shown in Table 1. The steel slag was taken from a steel plant in Qingdao, China, and ground into a powder $(<80 \mu \mathrm{m})$. The composition of steel slag measured by $\mathrm{X}$-ray fluorescence spectroscopy (XRF) is shown in Table 2. The main chemicals used in the research are potassium dichromate $\left(\mathrm{K}_{2} \mathrm{Cr}_{2} \mathrm{O}_{7}, A R\right)$, diphenylcarbazide $\left(\mathrm{C}_{13} \mathrm{H}_{14} \mathrm{~N}_{4} \mathrm{O}\right.$, AR), sulfuric acid $\left(\mathrm{H}_{2} \mathrm{SO}_{4}, \mathrm{AR}\right)$, and phosphoric acid $\left(\mathrm{H}_{3} \mathrm{PO}_{4}\right.$, AR), which are produced by Tianjin Guangcheng Chemical Reagent Co., Ltd.

\section{GA Experiments and Kinetic Analysis TG Experiment}

We used a thermogravimetric analyzer (METTLER TGA/DSC1) to pyrolyze sludge and steel slag. The accuracy of the thermometer is $\pm 0.2 \mathrm{~K}$, and the sensitivity of the microbalance is less than $\pm 0.1 \mu \mathrm{g}$. The pyrolysis process is carried out under a nitrogen atmosphere with a purity of $99 \%$ and a flow rate of $20 \mathrm{ml} / \mathrm{min}$. Each sample is kept at $10 \pm 0.1 \mathrm{mg}$ to alleviate heatand mass-transfer limitations. The initial temperature is room temperature, the end temperature is $900^{\circ} \mathrm{C}$, and the heating rate is set to $15 \mathrm{C} / \mathrm{min}$. Pyrolysis was carried out with pure sludge (DS) and sludge steel slag with ratios of 1:4 (SS 20\%), 2:3 (SS 40\%), 3:2 (SS 60\%), and 4:1 (SS 80\%). 
TABLE 1 | Characteristics of bagasse and sludge on a dry basis.

\begin{tabular}{|c|c|c|c|c|c|c|c|c|}
\hline \multirow[t]{2}{*}{ Samples } & \multicolumn{3}{|c|}{ Ultimate analysis $(w t \%)^{a}$} & \multicolumn{5}{|c|}{ Proximate analysis (wt\%) } \\
\hline & Volatile & Ash & Fixed carbon & C & $\mathbf{H}$ & $\mathbf{N}$ & $\mathbf{s}$ & 0 \\
\hline Sewage sludge & 52.03 & 39.94 & 8.03 & 25.44 & 4.29 & 4.37 & 1.30 & 26.47 \\
\hline
\end{tabular}

${ }^{a}$ According to the method of coal industry analysis in China (Chinese standard methods, GB/T 212-2008).

TABLE 2 | Chemical composition of steel slag.

\begin{tabular}{lllllllll} 
Samples & \multicolumn{8}{c}{ Chemical composition } \\
\cline { 2 - 8 } & $\mathbf{C a O}$ & $\mathbf{S i O}_{\mathbf{2}}$ & $\mathbf{F e}_{\mathbf{2}} \mathbf{O}_{\mathbf{3}}$ & $\mathbf{A l}_{\mathbf{2}} \mathbf{O}_{\mathbf{3}}$ & $\mathbf{M g O}$ & $\mathbf{M n O}$ & $\mathbf{S O}_{\mathbf{3}}$ & Others \\
\hline Steel slag & 38.59 & 34.50 & 12.18 & 2.45 & 7.03 & 2.97 & 1.45 & 0.83
\end{tabular}

The kinetic parameters obtained from thermogravimetric analysis are often used to evaluate the thermal behavior of materials under isothermal or non-isothermal conditions. Under the non-isothermal boundary conditions, the degradation of the sludge may also be understood as comprising a heterogeneous solid-phase reaction with a complex reaction mechanism. In order to understand the mechanism of kinetics, the kinetic equation of the solid reaction was first established, and then, the effective kinetic parameters were solved by the nonlinear optimization method.

The solid-state degradation of sewage sludge as a single reaction can be represented as (Naqvi et al., 2018)

$$
\text { Sewage Sludge }(\mathrm{s}) \rightarrow \text { Biochar }(\mathrm{s})+\text { Volatile }(\mathrm{g})
$$

The rate equation of the solid reaction can be described by the following formula:

$$
\frac{d \alpha}{d t}=k f(\alpha)
$$

where $k$ is the rate constant, $f(\alpha)$ is the kinetic model, $t$ is the reaction time, and $\alpha$ is the extent of conversion. Also, $\alpha$ is defined in terms of mass loss as

$$
\alpha=\frac{w_{0}-w}{w_{o}-w_{\infty}}
$$

where $w_{0}$ is the initial mass of the precursor, $\mathrm{w}$ is the instantaneous mass, and $w_{\infty}$ is the remaining mass of the material.

$f(\alpha)$ is a function related only to the reaction mechanism. If the effect of temperature on the activation energy is ignored, then $f(\alpha)=(1-\alpha)^{n}$, where $\mathrm{n}$ is the reaction order of the reaction. From the Arrhenius equation that expresses the relationship between chemical reaction rate and temperature, the formula can be obtained

$$
k=A e^{-\frac{E}{R T}}
$$

where $\mathrm{A}$ is the frequency factor, $\mathrm{E}$ is the activation energy, $\mathrm{R}$ is the ideal gas constant, and $\mathrm{T}$ is the absolute temperature.

Bringing Eq. 4 to Eq. 2, Eq. 2 becomes

$$
\frac{d \alpha}{d t}=A e^{-\frac{E}{R T}}(1-\alpha)^{n}
$$

According to the Coats-Redfern equation (Zaker et al., 2021), the heating rate $\beta=\frac{d \alpha}{d t}$ a is a fixed value, which can be put into Eq. 4 and sorted out to get

$$
\int_{0}^{\alpha} \frac{d \alpha}{f(\alpha)}=\frac{A}{\beta} \int_{T_{0}}^{T} e^{-\frac{E}{R T}} d T
$$

According to the method of Friedman (Friedman, 1964), the logarithm form is adopted for Eq. $\mathbf{6}$

$$
\ln \left[\frac{1-(1-\alpha)^{1-n}}{(1-n) T^{2}}\right]=\ln \left[\left(\frac{A R}{\beta E}\right)\left(1-\frac{2 R T}{E}\right)\right]-\frac{E}{R T}
$$

For the general reaction temperature range and most $\mathrm{E}$ values, $\frac{E}{R T}>>1$, therefore, $1-\frac{2 R T}{E} \approx 1$, then

$$
\begin{gathered}
\mathrm{n} \neq 1 \quad \ln \left(\frac{1-(1-\alpha)^{1-n}}{(1-n) T^{2}}\right)=\ln \left(\frac{A R}{\beta E}\right)-\frac{E}{R T} \\
\mathrm{n}=1 \quad \ln \left(-\frac{\ln (1-\alpha)}{T^{2}}\right)=\ln \left(\frac{A R}{\beta E}\right)-\frac{E}{R T}
\end{gathered}
$$

Equations 8, 9 can be written as a straight line $(y=a x+b) .1 / T$ equals $\mathrm{X}, \ln \left(\frac{1-(1-\alpha)^{1-n}}{(1-n) T^{2}}\right)$ and $\ln \left(-\frac{\ln (1-\alpha)}{T^{2}}\right)$ are considered as $\mathrm{y}$. Thus, the activation energy $\mathrm{E}$ can be obtained from the slope of the straight line, and the pre-exponential factor a can be obtained from its intercept. In this paper, the step size of $\mathrm{n}$ is 0.5 , and the reaction order $\mathrm{n}$ is determined in the interval of $0-3$ according to the principle of large absolute values of the correlation coefficient.

\section{Pyrolysis Experiment}

The pyrolysis experiment was carried out in a tube furnace (skgl1200-II). The length of the quartz tube in the tube furnace was $1500 \mathrm{~mm}$, and the inner diameter was $73 \mathrm{~mm}$. About $5.000 \pm$ $0.005 \mathrm{~g}$ of the raw material loaded into the quartz vessel is placed in the quartz tube. In order to form an oxygen-free atmosphere before pyrolysis, $0.5 \mathrm{~L} / \mathrm{min}_{2}$ was added into the system as a carrier gas for $10 \mathrm{~min} . \mathrm{N}_{2}$ was added in the whole pyrolysis process to maintain an inert atmosphere. Under the heating rate of $15 \mathrm{C} / \mathrm{min}$, the initial temperature was room temperature, the final temperature was $700^{\circ} \mathrm{C}$, and the temperature was kept for $30 \mathrm{~min}$. DS, SS $20 \%$, SS $40 \%$, SS 60 , and SS $80 \%$ were made into adsorbents for standby. Then, the raw materials mixed with sludge and steel slag in the same ratio were prepared into adsorbents under the same conditions, but the final temperatures were $300^{\circ} \mathrm{C}, 400^{\circ} \mathrm{C}, 500^{\circ} \mathrm{C}, 600^{\circ} \mathrm{C}$, and $700^{\circ} \mathrm{C}$, respectively. 


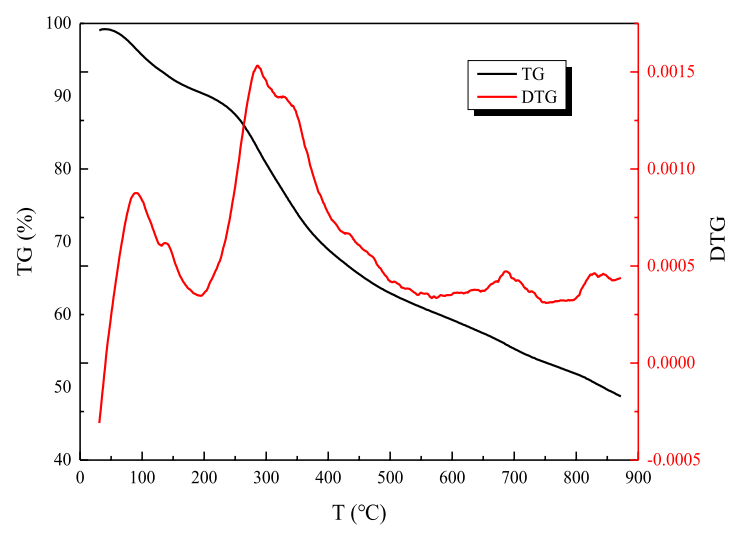

FIGURE 1 | TG-DTG curve of sewage sludge.

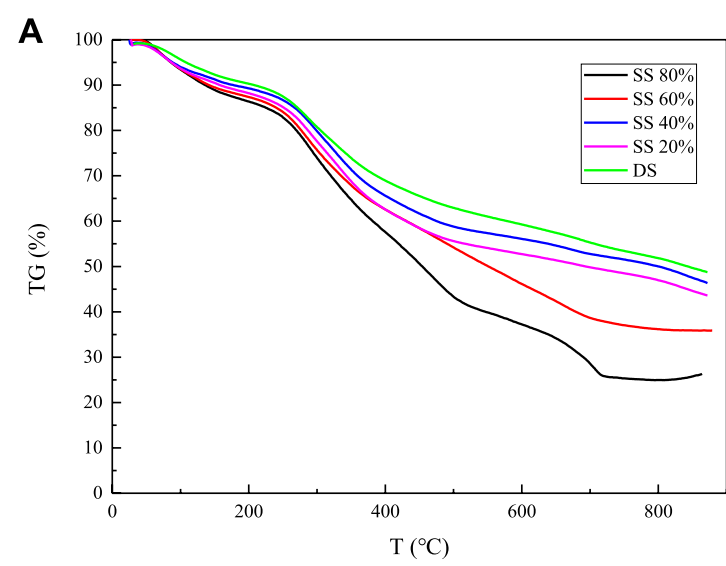

B

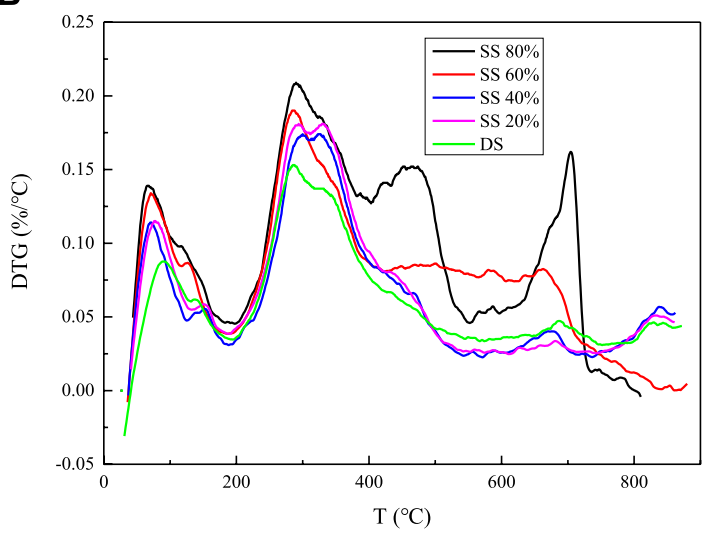

FIGURE 2 | Thermogravimetric analysis of sludge and steel slag with different mixing ratios: (A) TG curve and (B) DTG curve.

\section{Adsorption Experiment}

$0.2829 \mathrm{~g}$ of potassium dichromate $\left(\mathrm{K}_{2} \mathrm{Cr}_{2} \mathrm{O}_{7} ; \mathrm{AR}\right)$ was dissolved in a beaker with distilled water and poured into a $1 \mathrm{~L}$ volumetric flask to make $0.1 \mathrm{mg} \cdot \mathrm{ml}^{-1} \mathrm{Cr}(\mathrm{VI})$ standard solution. We used a dilute $\left(\mathrm{K}_{2} \mathrm{Cr}_{2} \mathrm{O}_{7} ; \mathrm{AR}\right)$ standard solution with distilled water to prepare $5 \mathrm{mg} / \mathrm{L}$ simulated wastewater. All adsorption experiments were carried out in a $250 \mathrm{ml}$ conical flask at room temperature. The conical flask contained $100 \mathrm{ml}$ of simulated wastewater. $500 \mathrm{mg}$ of adsorbents of different components was added. After labeling, they were placed at a $160 \mathrm{r} / \mathrm{min}$ rotating speed. On the centrifuge, the centrifugation time is $12 \mathrm{~h}$. The sample was filtered through a filter paper and a funnel, and the absorbance was measured by diphenylcarbazide spectrophotometry, and then, the concentration of chromium ions in the filtrate was analyzed. All adsorption experiments are repeated. Also, the adsorption rate of chromium ions $\Phi$ (\%; removal efficiency) is as follows:

$$
\Phi=\frac{C_{0}-C}{C_{0}} \times 100 \%
$$

where $\Phi$ is the removal efficiency, $c_{0}$ is the initial concentration of $\mathrm{Cr}(\mathrm{VI})$ in the solution $\left(\mathrm{mg} \cdot \mathrm{L}^{-1}\right)$, and $C$ is the concentration of $\mathrm{Cr}(\mathrm{VI})$ at time $\mathrm{t}$ of adsorption $\left(\mathrm{mg} \cdot \mathrm{L}^{-1}\right)$.

\section{Characteristic Description}

The specific surface areas of sludge with different blending ratios and slag were made by $\mathrm{N}_{2}$ adsorption (at $77 \mathrm{~K}$ ) were determined using a surface analyzer (Micromeritics, ASAP 2460). Before the desorption procedure, the adsorbent was degassed at $320^{\circ} \mathrm{C}$ for $4 \mathrm{~h}$ under vacuum. The SEM images of the samples with different pyrolysis temperatures were obtained using a German Merlin high-resolution field emission scanning electron microscope. $\mathrm{X}$-ray photoelectron spectroscopy (XPS; 250XI) was used to analyze the surface valence state and structure of the SS60\% adsorbent before and after adsorption and explore its adsorption mechanism for $\mathrm{Cr}(\mathrm{VI})$.

\section{RESULTS AND DISCUSSION}

\section{Thermogravimetric Analysis}

As can be seen from Figure 1, there are three weight loss peaks during the pyrolysis reaction of simple sludge components, that is, pyrolysis is divided into three parts. The first stage of the weight loss peak starts at about $60^{\circ} \mathrm{C}$, and the weight loss process is short and the rate is low until about $200^{\circ} \mathrm{C}$, which is a process of water evaporation and separation in the sludge. In the second stage, the weightlessness begins at $200^{\circ} \mathrm{C}$, and the weight loss process is longer and the rate is faster until about $550^{\circ} \mathrm{C}$. This is caused by the transformation reaction of aliphatic compounds, protein, and carbohydrate compounds in the sludge, the breaking of peptide bonds and branched chains, and the release of a large number of volatiles (Magdziarz and Wilk, 2013). The third stage of weightlessness is between $550^{\circ} \mathrm{C}$ and $750^{\circ} \mathrm{C}$, which is caused by the decomposition of residual organic salts in the sludge components.

It can be seen from the TG curve in Figure 2 that the curve of pure sludge is the flattest, and after mixing with steel slag, as the mixing ratio increases, the curve gradually becomes steeper and the end point of the curve becomes lower and lower. It shows that the degree of pyrolysis of sludge has also increased, and the maximum increase is about $20 \%$. From the DTG curve, we compared with pure sludge in the first stage, second stage, and third stage of the pyrolysis reaction. In the first stage, the peaks 
TABLE 3 | Calculation results of the sludge cracking mechanism model.

\begin{tabular}{|c|c|c|c|c|c|}
\hline $\begin{array}{l}\text { Order of } \\
\text { reaction }\end{array}$ & Slope & Intercept & $\begin{array}{l}\text { Correlation } \\
\text { coefficient }\end{array}$ & $\begin{array}{c}\text { Frequency } \\
\text { factor }\end{array}$ & $\begin{array}{c}\text { Activation } \\
\text { energy }\end{array}$ \\
\hline $\mathbf{n}$ & $\mathbf{a}$ & b & $\mathbf{R}^{2}$ & A & $\mathrm{E} /(\mathrm{KJ} / \mathrm{mol})$ \\
\hline 0.5 & -1053.8805 & -11.8384 & 0.8923 & 0.1142 & 8.7619 \\
\hline 1 & -1366.1729 & -11.1790 & 0.9381 & 0.2864 & 11.3583 \\
\hline 1.5 & -1709.4628 & -10.4610 & 0.9639 & 0.7349 & 14.2124 \\
\hline 2 & -2083.4348 & -9.6822 & 0.9787 & 1.9514 & 17.3216 \\
\hline 2.5 & -2487.1711 & -8.8471 & 0.9873 & 5.3696 & 20.6783 \\
\hline 3 & -2919.2295 & -7.9537 & 0.9960 & 15.3972 & 24.2704 \\
\hline
\end{tabular}

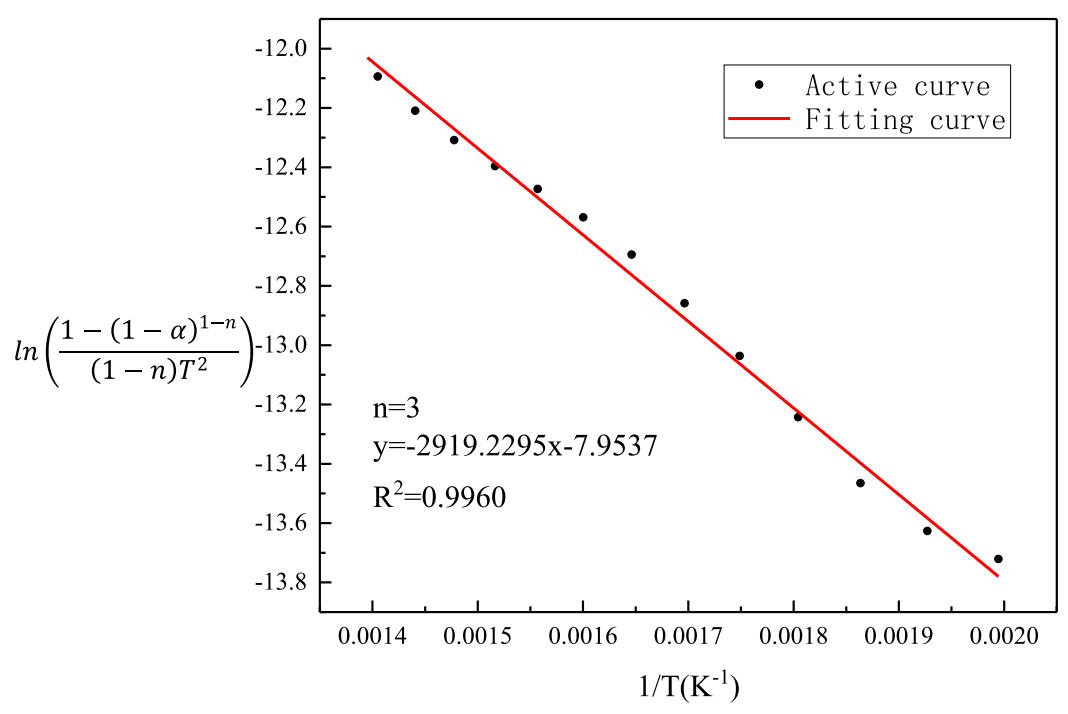

FIGURE 3 | Fitting diagram of sludge pyrolysis kinetics.

TABLE 4 | Calculation results of different ratios of sludge and steel slag cracking mechanism models.

\begin{tabular}{|c|c|c|c|c|c|}
\hline $\begin{array}{l}\text { Steel slag } \\
\text { content }\end{array}$ & Slope & Intercept & $\begin{array}{l}\text { Correlation } \\
\text { coefficient }\end{array}$ & Frequency factor & $\begin{array}{c}\text { Activation } \\
\text { energy }\end{array}$ \\
\hline$\%$ & $\mathbf{a}$ & b & $\mathbf{R}^{2}$ & A & $\mathrm{E} /(\mathrm{KJ} / \mathrm{mol})$ \\
\hline 20 & -3159.2788 & -7.5204 & 0.9944 & 25.7009 & 26.2662 \\
\hline 40 & -3345.5029 & -7.2140 & 0.9933 & 36.9701 & 27.8145 \\
\hline 60 & -3534.1110 & -6.8288 & 0.9960 & 57.4046 & 29.3825 \\
\hline 80 & -3701.8138 & -6.5491 & 0.9971 & 79.5302 & 30.7768 \\
\hline
\end{tabular}

are all increased, the peaks are sharper, and the peak area becomes larger. The first stage does not increase in proportion, and the increase is about $26 \%$ of the pure sludge. This indicates that the internal sludge is contained in the sludge after adding steel slag. The rate of water release has increased and is more obvious. From the point of view of weight loss rate, the mixing of steel slag increases the evaporation of internal water. When the content of steel slag is $80 \%$, the change is the largest, increasing from 9.5 to $16.1 \%$; In the second stage of the pyrolysis process, the maximum weight loss rate is increased, reaching the maximum when the steel slag content is $80 \%$, and the rate is increased by about one- third. When the content is $60 \%$, the rate is slightly lower, but the weight loss rate reaches the maximum value, which is increased from $29 \%$. As much as $41 \%$, the maximum rate and weight loss rate in the third stage change positively with the content of steel slag. When the content of steel slag is $80 \%$, both reach the maximum, increasing by 245 and $80 \%$, respectively.

In fact, the above-mentioned changes are caused because the steel slag contains a large amount of metal oxides such as $\mathrm{CaO}$ and $\mathrm{Fe}_{2} \mathrm{O}_{3}$. $\mathrm{CaO}$ itself can react with free water molecules and release heat, and it has a very high melting point. In the low-temperature stage of sludge pyrolysis, the $\mathrm{H}_{2} \mathrm{O}$ released as the temperature rises 

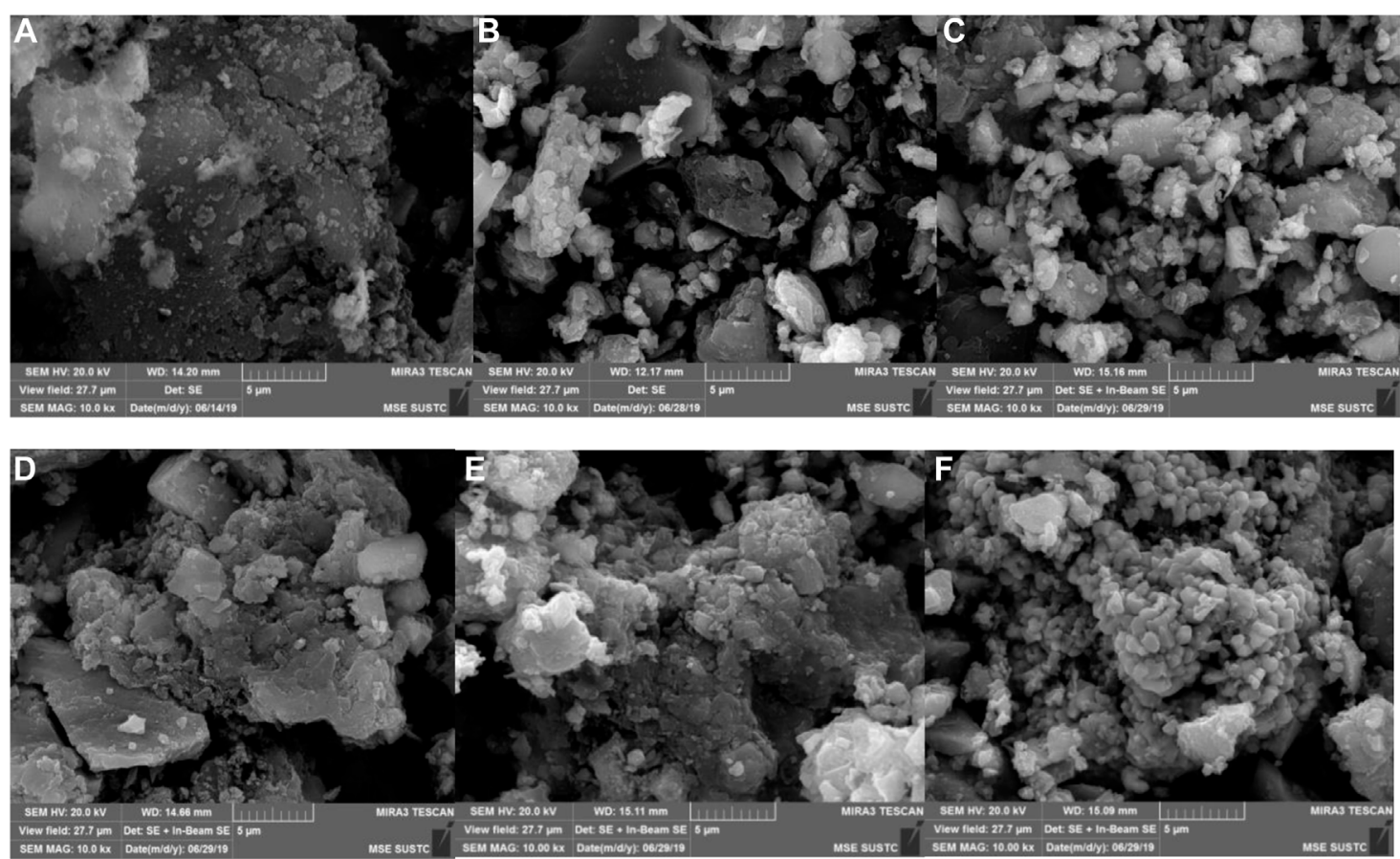

FIGURE 4 | SEM images of various stages of pyrolysis of sludge and steel slag: (A) DS, (B) $300^{\circ} \mathrm{C} \mathrm{SS}$, (C) $400^{\circ} \mathrm{C} \mathrm{SS}$, (D) $500^{\circ} \mathrm{C} \mathrm{SS}$, (E) $600^{\circ} \mathrm{C} \mathrm{SS}$, and (F) $700^{\circ} \mathrm{C} \mathrm{SS}$.

is released from the sludge and is converted from the bound state. It is a free state, and then, after contact with $\mathrm{CaO}$, a chemical reaction occurs and energy is released, and it also provides a part of energy for the pyrolysis of sludge so that the reaction rate and weight loss rate of the first stage are increased. At the same time, when the pyrolysis temperature reaches $650 \sim 750^{\circ} \mathrm{C}$, a large amount of $\mathrm{CO}_{2}$ is generated and precipitated. This part of the gas is absorbed by $\mathrm{CaO}$, thereby increasing the weight loss rate and the reaction rate. $\mathrm{CaO}$ may react as follows during pyrolysis: $\left(\mathrm{CaO}+\mathrm{H}_{2} \mathrm{O} \rightarrow \mathrm{Ca}(\mathrm{OH})_{2} ; \mathrm{Ca}(\mathrm{OH})_{2}+\mathrm{CO}_{2} \rightarrow \mathrm{CaCO}_{3}+\mathrm{H}_{2} \mathrm{O}\right)$. $\mathrm{Fe}_{2} \mathrm{O}_{3}$ is oxidizing and may react with $\mathrm{H}_{2}$ and $\mathrm{CO}$ from sludge pyrolysis under high-temperature conditions $\left(\mathrm{Fe}_{2} \mathrm{O}_{3}+3 \mathrm{H}_{2} \rightarrow 2 \mathrm{Fe}+3 \mathrm{H}_{2} \mathrm{O} ; \mathrm{Fe}_{2} \mathrm{O}_{3}+3 \mathrm{CO} \rightarrow 2 \mathrm{Fe}+3 \mathrm{CO}_{2}\right)$, and part of $\mathrm{H}_{2}$ and $\mathrm{CO}$ were absorbed, which accelerated the reaction rate and weight loss rate to a certain extent.

\section{Pyrolysis Kinetic Analysis}

It can be seen from Table 3 that when $n=3$, the fitted linear correlation coefficient $\mathrm{R}^{2}=0.9960$ is the highest, and the frequency factor $\mathrm{A}=15.3972$ is the largest. Therefore, the kinetic model function of sludge pyrolysis is $f(\alpha)=(1-\alpha)^{3}$. The regression equation is $y=2919.2295 x-7.9537$. Also, the fitted image is shown in Figure 3.

Using the same mathematical model and calculation method, $n=3$, the kinetic calculation of the pyrolysis process of the sludge steel slag mixture mixed with different proportions of steel slag is carried out. The obtained kinetic parameters and activation energy are shown in Table 4.

It can be seen from Table 4 that the activation energy of the main reaction stage increases after mixing steel slag, and the activation energy increases from $24.2704 \mathrm{~kJ} / \mathrm{mol}$ to $30.7768 \mathrm{~kJ} /$ mol with the increase of steel slag content. The maximum increase is up to $26.8 \%$, and this increase gradually increases with the change of steel slag content. It can be seen from Table 2 that $\mathrm{CaO}$ accounts for $38.59 \%$ of the total composition of steel slag and $\mathrm{SiO}$ accounts for $34.50 \%$ of the total composition of steel slag. According to the conclusion of thermogravimetric analysis, the existence of $\mathrm{CaO}$ can promote the decomposition and release of organic matter such as $\mathrm{CH}_{4}$ in the main stage of pyrolysis. The role of $\mathrm{CaO}$ in the activation energy is reduced, and there are metal oxides in steel slag. However, a high content of $\mathrm{SiO}_{2}$ does not have catalytic performance, and to a certain extent, it hinders the heat and mass transfer inside the sludge particles, hinders the pyrolysis reaction, and increases the activation energy. It can be deduced that $\mathrm{SiO}_{2}$ will play a certain inhibitory effect in the main stage of sludge pyrolysis. This effect increases gradually with the increase of $\mathrm{SiO}_{2}$ content, and the final activation energy increases or decreases are the results of multiple factors. Here, the incorporation of steel slag increases the activation energy of sludge and inhibits pyrolysis.

\section{Micromorphology and Specific Surface Areas of the Adsorbent}

It can be seen from Figure $\mathbf{4}$ from the surface morphology diagrams of each stage of pyrolysis that the surface of the sludge itself is relatively dense, and the particles are very rare. After being mixed with steel slag and pyrolyzed together, as the pyrolysis temperature increased, there was a very obvious change that a lot of particles appeared on the surface of the residue, and 

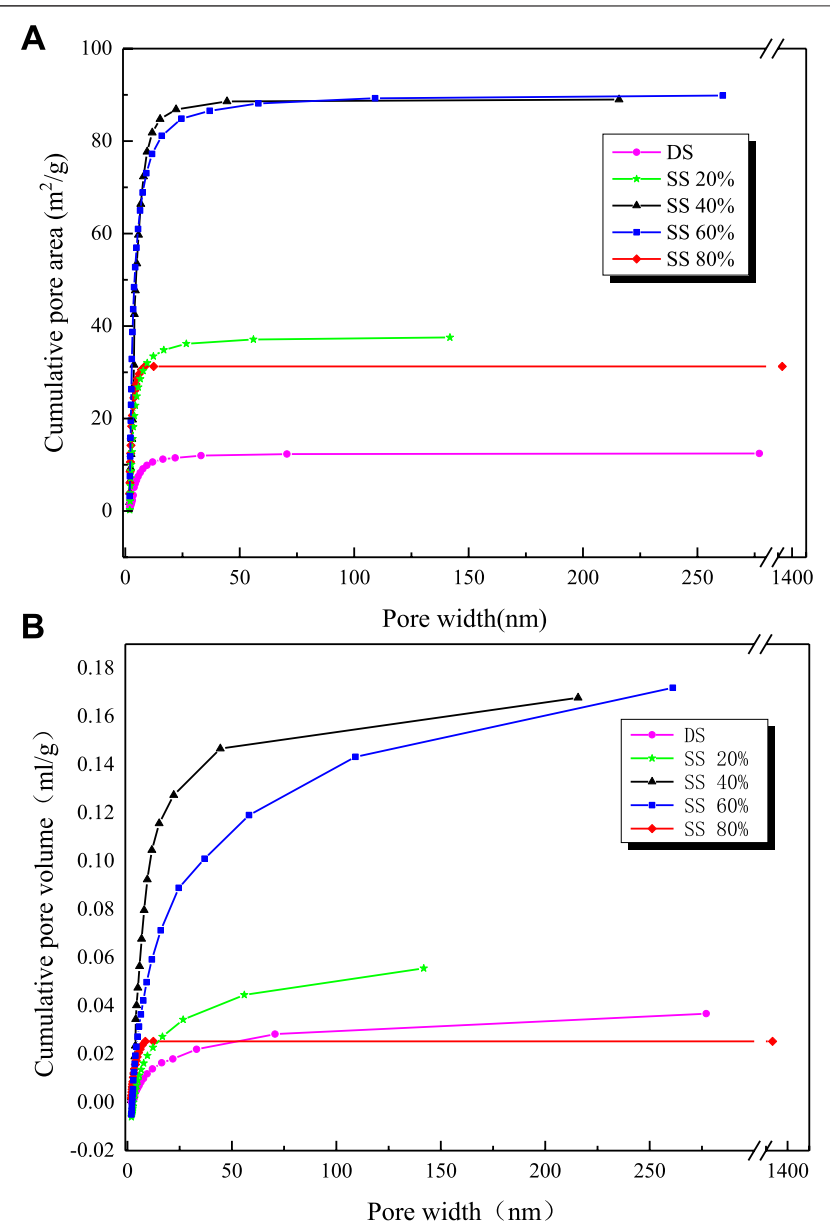

FIGURE 5 | Adsorption pore volume and pore area distribution curve of different mixing ratios of sludge and steel slag: $(\mathbf{A})$ pore area and $\mathbf{( B )}$ pore volume.

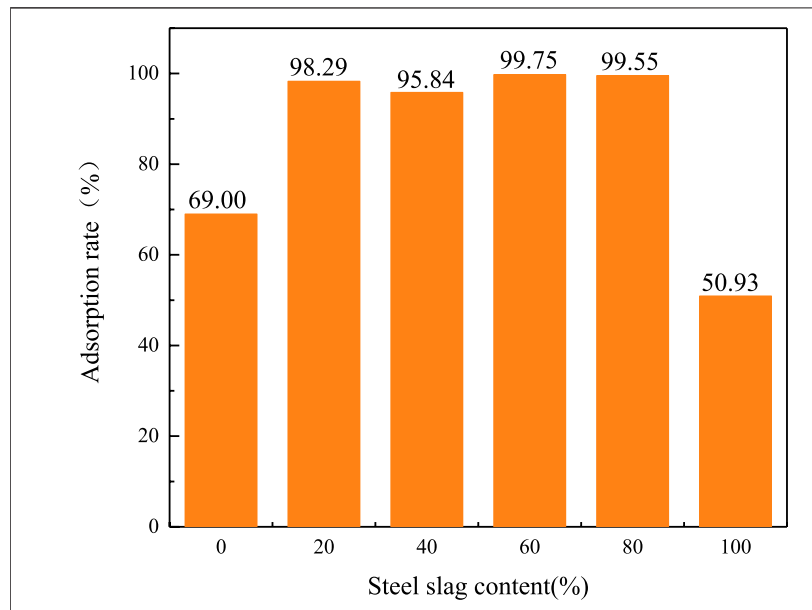

FIGURE 6 | Adsorption rate of sludge and steel slag with different mixing ratios of the adsorbent to $\mathrm{Cr}(\mathrm{VI})$ in solution

of metal oxide groups and forms clusters with certain morphological characteristics.

\section{Specific Surface Area and Pore Structure of the Adsorbent}

It can be seen in Figure 5 that the curve grows most rapidly within 0-50 $\mathrm{nm}$ after pyrolysis of pure sludge, the curve basically tends to be flat after $75 \mathrm{~nm}$, and most of the points are concentrated between $0 \sim 75 \mathrm{~nm}$, which shows that most of the average pore size of the pyrolysis residue is below $75 \mathrm{~nm}$ and the maximum pore size is about $275 \mathrm{~nm}$. After adding steel slag, the slope of the adsorption pore volume curve increases compared with pure sludge, and the curve trend is closer to the Y-axis. It can be judged that the pore size of the mixed residue is

TABLE 5 | Pore size distribution parameters of adsorbents with different contents of steel slag.

\begin{tabular}{lcc}
$\begin{array}{l}\text { Steel slag } \\
\text { content }\end{array}$ & $\mathbf{0}$ & $\mathbf{2 0 \%}$ \\
\hline BET: $\mathrm{m}^{2} / \mathrm{g}$ & & 36.3528 \\
Total pore volume: $\mathrm{m}^{2} / \mathrm{g}$ & 12.4400 & 0.0563 \\
Average hole diameter: $\mathrm{nm}$ & 0.0368 & 7.500 \\
Most probable aperture: $\mathrm{nm}$ & 11.8300 & 3.8100 \\
D10 pore diameter: $\mathrm{nm}$ & 3.8800 & 2.9400 \\
D90 pore diameter: $\mathrm{nm}$ & 3.6900 & 34.1100
\end{tabular}

the dense surface became fluffy. After $500^{\circ} \mathrm{C}$, the pores became larger and larger, which can be explained by that the pyrolysis reaction of the sludge progresses, and a large amount of volatiles are released after the temperature rises. The dense surface collapses and a large number of ravines are produced, which provides considerable adsorption possibilities for the adsorbent. However, the steel slag reacts with the sludge, and the pyrolysis temperature of $600-700^{\circ} \mathrm{C}$ strengthens the enrichment of heavy metals in the sludge. The concentration causes the precipitation relatively reduced. It can be seen from Table 5 that the total pore volume of the mixture is larger than that of pure sludge, and it increases first and then decreases with the increase of steel slag content. When the steel slag content is 40 and $60 \%$, the maximum is about 5 times of pure sludge, and the average pore diameter decreases. When the steel slag content was 80 $\%$, it reached the minimum value of $4.1500 \mathrm{~nm}$, which reduced about $60 \%$ of the pure sludge, while the average pore diameter of the other three groups had little difference. The most probable 

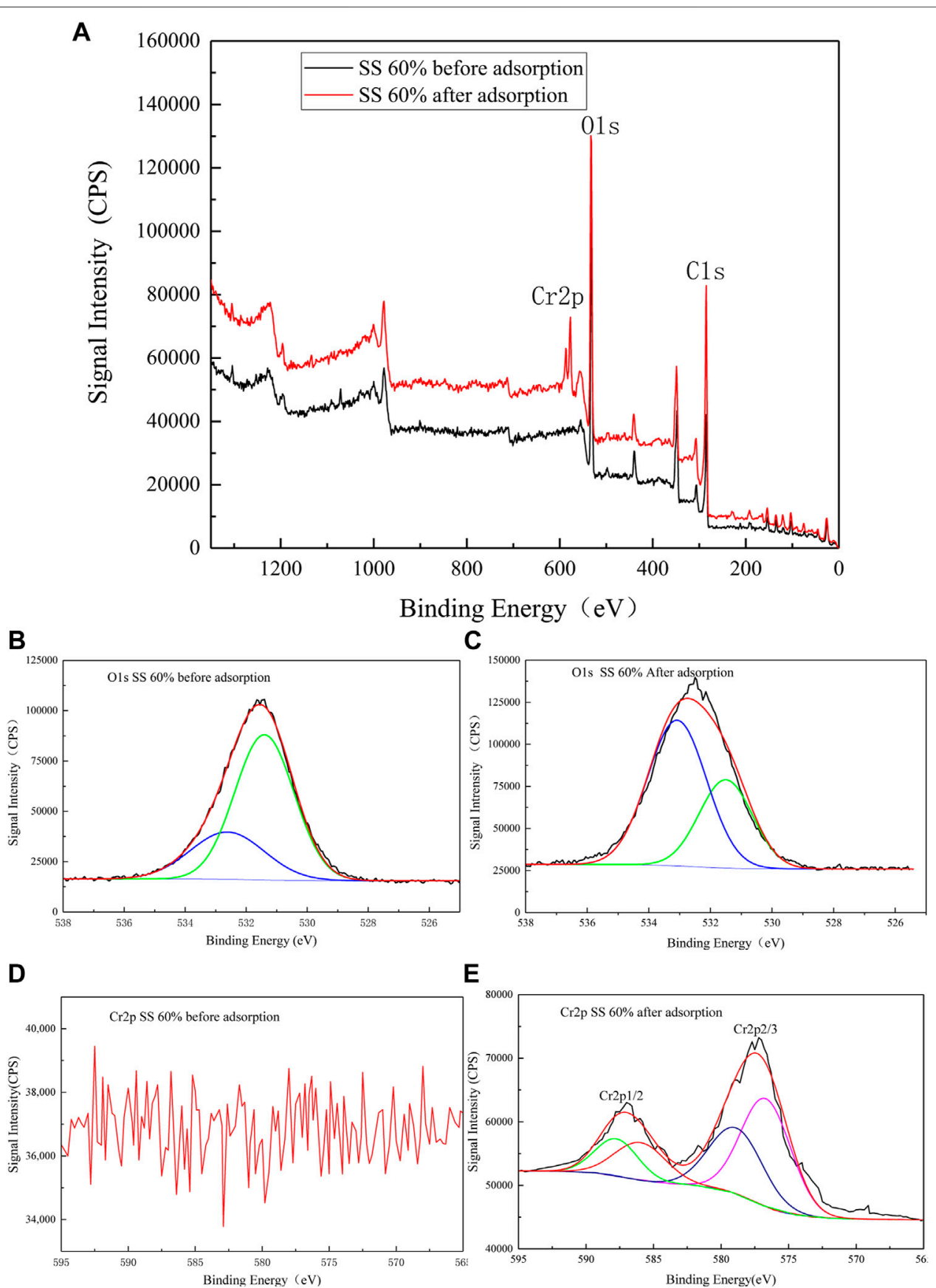

FIGURE 7|XPS spectra (A) SS 60\% before and after adsorption of Cr(VI). (B) O1s SS 60\% before adsorption. (C) O1s SS 60\% after adsorption. (D) Cr2p SS 60\% before adsorption. (E) Cr2p SS 60\% after adsorption.

diameter is basically unchanged. From the point of view of the diameter of the $\mathrm{D} 90$ hole, the change after mixing is large. The diameter of the $\mathrm{D} 90$ hole of the pure sludge is $99.2700 \mathrm{~nm}$. As the amount of steel slag mixed increases, the diameter of the D90 hole decreases to between $23 \sim 34 \mathrm{~nm}$. The rate is $66 \sim 77 \%$. The change of the specific surface area is also very obvious, and its change trend is consistent with the total pore volume. It first increases and then decreases. When the steel slag content is $80 \%$, the minimum is $31.8990 \mathrm{~m}^{2} / \mathrm{g}$, and the growth rate is $158 \%$. At $40 \%$, the maximum is $88.7830 \mathrm{~m}^{2} / \mathrm{g}$, and the growth rate is $616 \%$.

Combined with the analysis results of the pictures obtained by scanning electron microscopy, after the sludge and steel slag are mixed, the steel slag powder is dispersed and attached to the surface of the sludge, causing a lot of irregular protrusions on the 
surface of the mixture, and then undergoes high-temperature pyrolysis. Analyzing the moisture and volatilization contained in the sludge, the inside and surface of the sludge collapsed, and many macroporous structures appeared. At the same time, the enhancement of the enrichment of metal oxides by the sludge at high temperature makes this part of the material fill the sludge itself and the newly formed macroporous structure and disperse it into a number of relatively small mesopores. These changes also made the originally dense surface and became fluffy and porous, thus increasing the specific surface area of the mixture. However, as the steel slag content becomes larger and larger and the proportion reaches $80 \%$, a large amount of steel slag filling makes the surface ravines of the sludge and the macroporous structure produced by pyrolysis gradually fill up and disappear, and the increase in the specific surface area of the product gradually decreases. It is even smaller than when it is not added. Therefore, in terms of specific surface area, it is not that the larger the amount of steel slag blended, the better the adsorption performance of the obtained adsorbent. A proper amount of steel slag blending will increase the specific surface area of the mixture and reduce its pore size range. The best blending amount is between 40 and $60 \%$.

\section{Adsorption Experiment}

The results of adsorption experiments (Figure 6) exhibited that the sludge and steel slag after pyrolysis alone have a certain adsorption capacity for chromium ions, but the adsorption rate is not high. The adsorption rates of the steel slag and sludge for $\mathrm{Cr}(\mathrm{VI})$ are 50.93 and 69\%, respectively. Nevertheless, the $\mathrm{Cr}(\mathrm{VI})$ adsorption rate of the product obtained from pyrolysis of the mixture of steel slag and sludge improves greatly, and the adsorption rate increases above 95\%. When the steel slag content is $60 \%$, the adsorption rate is the highest up to $99.75 \%$. In fact, the adsorption rate of steel slag on $\mathrm{Cr}$ (III) is very high and the adsorption capacity of $\mathrm{Cr}(\mathrm{VI})$ is weak. The method in this paper can directly adsorb $\mathrm{Cr}(\mathrm{VI})$ with the blended pyrolysis residue and can also achieve an adsorption rate equivalent to $\mathrm{Cr}(\mathrm{III})$. On the one hand, the increase in specific surface area and surface wrinkles after blending pyrolysis greatly enhances its adsorption effect; on the other hand, the increase of metal oxides and the reducing groups generated after sludge pyrolysis are conducive to the affinity adsorption and reduction of $\mathrm{Cr}(\mathrm{VI})$ under a neutral $\mathrm{pH}$ environment.

\section{X-Ray Photoelectron Spectra Before and After SS 60\% Adsorption}

Figure 7A shows that the residues before and after adsorption contain the $\mathrm{C}$ and $\mathrm{O}$ elements. The adsorption peak of the $\mathrm{O}$ element changes significantly after adsorption, and the $\mathrm{Cr}$ peak appears in the full spectrum after adsorption. Figures $\mathbf{7 B}, \mathbf{C}$ are the energy spectra of $\mathrm{O} 1 \mathrm{~s}$ before and after adsorption. Before adsorption, 532.5 and $531.4 \mathrm{eV}$ are the binding energies of nonmetal oxide $\left(\mathrm{SiO}_{2}\right)$ and carbonate $\left(\mathrm{CaCO}_{3}\right)$, respectively. The binding energy after adsorption is converted to 533.1 and $531.5 \mathrm{eV}$, which are the binding energies of non-metal oxide
$\left(\mathrm{SiO}_{2}\right)$ and metal oxide $\left(\mathrm{Cr}_{2} \mathrm{O}_{3}\right)$, respectively, indicating that the $\mathrm{O}$ element participates in the adsorption process. Figure 7D is the Cr $2 \mathrm{p}$ energy spectrum before adsorption. It can be seen that there are all miscellaneous peaks and no $\mathrm{Cr} 2 \mathrm{p}$ peaks. Figure $7 \mathbf{E}$ is the $\mathrm{Cr} 2 \mathrm{p}$ energy spectrum after adsorption. The binding energies of $\mathrm{Cr} 2 \mathrm{p} 3 / 2$ and $\mathrm{Cr} 2 \mathrm{p} 1 / 2$ are respectively 577.2 and $587 \mathrm{eV}$. Cr $2 \mathrm{p} 3 / 2$ can be peaked to fit $\mathrm{Cr}(\mathrm{VI})$ and $\mathrm{Cr}(\mathrm{III})$, and its binding energy is 578.4 and $576.6 \mathrm{eV}$, respectively; $\mathrm{Cr} 2 \mathrm{p} 1 / 2$ can be peaked to fit $\mathrm{Cr}(\mathrm{VI})$ and $\mathrm{Cr}(\mathrm{III})$ and its combination. The energy is 587.5 and $5861 \mathrm{eV}$, respectively (Ai et al., 2008). This may be due to the presence of some highly reducing components (such as zero-valent iron) in the adsorbent, which reduces a part of $\mathrm{Cr}(\mathrm{VI})$ to $\mathrm{Cr}(\mathrm{III})$ through an oxidation-reduction reaction. This shows that the adsorption mechanism of the adsorbent to $\mathrm{Cr}(\mathrm{VI})$ is controlled by both physical and chemical processes.

\section{CONCLUSION}

The sludge-based adsorbent was prepared by blending pyrolysis of sludge with steel slag. It was found that the adsorbent had a good adsorption effect on $\mathrm{Cr}(\mathrm{VI})$. When steel slag accounted for $60 \%$, the removal capacity of $\mathrm{Cr}(\mathrm{NaCl})$ in the solution reached 99.75\%. Some metal oxides $\left(\mathrm{CaO}, \mathrm{Fe}_{2} \mathrm{O}_{3}\right)$ in steel slag can react with the gases $\left(\mathrm{H}_{2}, \mathrm{CO}\right)$ generated by sludge pyrolysis to promote sludge pyrolysis, while the high content of $\mathrm{SiO}_{2}$ in steel slag can increase the activation energy of sludge and inhibit sludge pyrolysis. At the same time, with the addition of steel slag, the pore structure of the sludge-based adsorbent becomes developed and the specific surface area doubles, and the optimal addition is when the steel slag ratio is $40-60 \%$. In addition, XPS analysis shows that the adsorption mechanism of $\mathrm{Cr}(\mathrm{VI})$ by the additive is controlled by both physics and chemistry.

\section{DATA AVAILABILITY STATEMENT}

The original contributions presented in the study are included in the article/Supplementary Material; further inquiries can be directed to the corresponding authors.

\section{AUTHOR CONTRIBUTIONS}

XQ designed the experiment and wrote the manuscript. EZ reviewed and revised the manuscript. XW processed the data and figures. SL developed the concept. YS revised the manuscript.

\section{FUNDING}

This work was supported by the Natural Science Foundation of Shandong Province, China (No. ZR2019MEE015) and 2020 science and technology project of Qingdao West Coast New Area (Science and technology benefiting the people) (No. 2020-99). 


\section{REFERENCES}

Ai, Z., Cheng, Y., Zhang, L., and Qiu, J. (2008). Efficient Removal of Cr(VI) from Aqueous Solution with Fe@Fe2O3 Core-Shell Nanowires. Environ. Sci. Technol. 42 (18), 6955-6960. doi:10.1021/es800962m

Barry, D., Barbiero, C., Briens, C., and Berruti, F. (2019). Pyrolysis as an Economical and Ecological Treatment Option for Municipal Sewage Sludge, Biomass and Bioenergy 122. 472-480. doi:10.1016/j.biombioe.2019.01.041

Bondarczuk, K., Markowicz, A., and Piotrowska-Seget, Z. (2015). The Urgent Need for Risk Assessment on the Antibiotic Resistance Spread via Sewage Sludge Land Application. Environment International 87, 49-55. doi:10.1016/j.envint.2015.11.011

Bora, A. P., Gupta, D. P., and Durbha, K. S. (2020). Sewage Sludge to Bio-Fuel: A Review on the Sustainable Approach of Transforming Sewage Waste to Alternative Fuel. Fuel 259, 116262. doi:10.1016/j.fuel.2019.116262

Cao, Y., and Pawłowski, A. (2012). Sewage Sludge-To-Energy Approaches Based on Anaerobic Digestion and Pyrolysis: Brief Overview and Energy Efficiency Assessment. Renewable and Sustainable Energy Reviews 16 (3), 1657-1665. doi:10.1016/j.rser.2011.12.014

Diao, J., Zhou, W., Ke, Z., Qiao, Y., Zhang, T., Liu, X., et al. (2016). System Assessment of Recycling of Steel Slag in Converter Steelmaking. Journal of Cleaner Production 125, 159-167. doi:10.1016/j.jclepro.2016.03.040

Fang, W., Wei, Y., and Liu, J. (2016). Comparative Characterization of Sewage Sludge Compost and Soil: Heavy Metal Leaching Characteristics. Journal of Hazardous Materials 310, 1-10. doi:10.1016/j.jhazmat.2016.02.025

Fernando, N. L., and Fedorak, P. M. (2005). Changes at an Activated Sludge Sewage Treatment Plant Alter the Numbers of Airborne Aerobic Microorganisms. Water Research 39 (19), 4597-4608. doi:10.1016/j.watres.2005.08.010

Friedman, H. L. (1964). Kinetics of thermal Degradation of Char-Forming Plastics from Thermogravimetry. Application to a Phenolic Plastic. J. Polym. sci., C Polym. Symp. 6 (1), 183-195. doi:10.1002/polc.5070060121

Jin, J., Li, Y., Zhang, J., Wu, S., Cao, Y., Liang, P., et al. (2016). Influence of Pyrolysis Temperature on Properties and Environmental Safety of Heavy Metals in Biochars Derived from Municipal Sewage Sludge. Journal of Hazardous Materials 320, 417-426. doi:10.1016/j.jhazmat.2016.08.050

Lee, S., Kim, S.-H., Jung, S., Park, Y.-K., Tsang, Y. F., and Kwon, E. E. (2020). Use of Steel Slag as a Catalyst in CO2-cofeeding Pyrolysis of pine Sawdust. Journal of Hazardous Materials 392, 122275. doi:10.1016/j.jhazmat.2020.122275

Li, F., Yan, B., Zhang, Y., Zhang, L., and Lei, T. (2014). Effect of Activator on the Structure and Desulphurization Efficiency of Sludge-Activated Carbon. Environmental Technology 35 (20), 2575-2581. doi:10.1080/21622515.2014.913689

Lin, Y., Liao, Y., Yu, Z., Fang, S., and Ma, X. (2017). A Study on Co-pyrolysis of Bagasse and Sewage Sludge Using TG-FTIR and Py-GC/MS, Energy Conversion and Management 151. 190-198. doi:10.1016/j.enconman.2017.08.062

Liu, J., Yu, B., and Wang, Q. (2020). Application of Steel Slag in Cement Treated Aggregate Base Course. Journal of Cleaner Production 269, 121733. doi:10.1016/ j.jclepro.2020.121733

Luo, S., Liu, L., Song, Y., Fang, L., Wang, J., Zuo, Z., et al. (2020). Effect of Activation Pretreatment on the Pyrolysis Behavior of Sludge. $j$ biobased mat bioenergy 14 (4), 461-466. doi:10.1166/jbmb.2020.1989

Magdziarz, A., and Wilk, M. (2013). Thermogravimetric Study of Biomass, Sewage Sludge and Coal Combustion. Energy Conversion and Management 75, 425-430. doi:10.1016/j.enconman.2013.06.016

Naqvi, S. R., Tariq, R., Hameed, Z., Ali, I., Taqvi, S. A., Naqvi, M., et al. (2018). Pyrolysis of High-Ash Sewage Sludge: Thermo-Kinetic Study Using TGA and Artificial Neural Networks. Fuel 233, 529-538. doi:10.1016/j.fuel.2018.06.089
Piatak, N. M., Parsons, M. B., and Seal, R. R. (2015). Characteristics and Environmental Aspects of Slag: A Review. Applied Geochemistry 57, 236-266. doi:10.1016/j.apgeochem.2014.04.009

Raheem, A., Sikarwar, V. S., He, J., Dastyar, W., Dionysiou, D. D., Wang, W., et al. (2018). Opportunities and Challenges in Sustainable Treatment and Resource Reuse of Sewage Sludge: A Review. Chemical Engineering Journal 337, 616-641. doi:10.1016/j.cej.2017.12.149

Sridhar, B., and Sastri, M. V. S. S. (2021). Studies on Strength and Behaviour of Hot Mix Asphalt Using Steel Slag Aggregates in Pavements. [J]. Key Engineering Materials 6211, 254-262. doi:10.4028/www.scientific.net/kem.882.254

Stunda-Zujeva, A., Kreicbergs, I., and Medne, O. (2018). Sustainable Utilization of Sewage Sludge: Review of Technologies. Kem 762, 121-125. doi:10.4028/ www.scientific.net/kem.762.121

Wang, Z., Liu, K., Xie, L., Zhu, H., Ji, S., and Shu, X. (2019). Effects of Residence Time on Characteristics of Biochars Prepared via Co-pyrolysis of Sewage Sludge and Cotton Stalks. Journal of Analytical and Applied Pyrolysis 142, 104659. doi:10.1016/j.jaap.2019.104659

Wei, L.-L., Zhao, Q.-L., Hu, K., Lee, D.-J., Xie, C.-M., and Jiang, J.-Q. (2011). Extracellular Biological Organic Matters in Sewage Sludge during Mesophilic Digestion at Reduced Hydraulic Retention Time. Water Research 45 (3), 1472-1480. doi:10.1016/j.watres.2010.11.003

Yang, Y.-Q., Cui, M.-H., Guo, J.-C., Du, J.-J., Zheng, Z.-Y., and Liu, H. (2010). Effects of Co-pyrolysis of rice Husk and Sewage Sludge on the Bioavailability and Environmental Risks of $\mathrm{Pb}$ and $\mathrm{Cd}$. Environmental technology 42, 2304-2312. doi:10.1080/09593330.2019.1701562

Zaker, A., Chen, Z., Zaheer-Uddin, M., and Guo, J. (2021). Co-pyrolysis of Sewage Sludge and Low-Density Polyethylene - A Thermogravimetric Study of ThermoKinetics and Thermodynamic Parameters. Journal of Environmental Chemical Engineering 9, 104554. doi:10.1016/J.JECE.2020.104554

Zhao, B., Xu, X., Zeng, F., Li, H., and Chen, X. (2018). The Hierarchical Porous Structure Bio-Char Assessments Produced by Co-pyrolysis of Municipal Sewage Sludge and Hazelnut Shell and Cu(II) Adsorption Kinetics. Environ Sci Pollut Res 25 (20), 19423-19435. doi:10.1007/ s11356-018-2079-y

Zuo, Z., Yu, Q., Luo, S., Zhang, J., and Zhou, E. (2019). Effects of CaO on Two-step Reduction Characteristics of Copper Slag Using Biochar as Reducer: Thermodynamic and Kinetics. Energy Fuels 34 (1), 491-500. doi:10.1021/ acs.energyfuels. $9 \mathrm{~b} 03274$

Conflict of Interest: The authors declare that the research was conducted in the absence of any commercial or financial relationships that could be construed as a potential conflict of interest.

Publisher's Note: All claims expressed in this article are solely those of the authors and do not necessarily represent those of their affiliated organizations or those of the publisher, the editors, and the reviewers. Any product that may be evaluated in this article or claim that may be made by its manufacturer is not guaranteed or endorsed by the publisher.

Copyright (C) $2022 \mathrm{Qi}, \mathrm{Zhou}, \mathrm{Wu}, \mathrm{Luo}$ and Song. This is an open-access article distributed under the terms of the Creative Commons Attribution License (CC BY). The use, distribution or reproduction in other forums is permitted, provided the original author(s) and the copyright owner(s) are credited and that the original publication in this journal is cited, in accordance with accepted academic practice. No use, distribution or reproduction is permitted which does not comply with these terms. 